\title{
क्ष Tumoral calcinosis of the craniovertebral junction as a cause of dysphagia with treatment by transoral decompression: case report
}

\author{
Michael A. Mooney, MD, Mark E. Oppenlander, MD, U. Kumar Kakarla, MD, and \\ Nicholas Theodore, MD \\ Department of Neurosurgery, Barrow Neurological Institute, St. Joseph's Hospital and Medical Center, Phoenix, Arizona \\ Tumoral calcinosis is characterized by tumor-like deposition of calcium in periarticular soft tissue. Spinal involvement \\ is rare, and perioperative diagnosis of tumoral calcinosis can be difficult because lesions may be confused with bony \\ neoplasms. Symptoms of tumoral calcinosis result from bony involvement and/or direct compression of surrounding \\ anatomical structures, for which treatment with surgical decompression can be highly successful. The craniovertebral \\ junction is rarely affected by tumoral calcinosis, and patients with this condition may present with distinct symptoms. \\ Herein, to their knowledge the authors present the first case of tumoral calcinosis affecting the craniovertebral junction in \\ a patient who presented with severe dysphagia and required transoral decompression. Recognition of tumoral calcinosis \\ by neurosurgeons is essential for facilitating diagnosis and treatment, and the transoral approach is an effective method \\ for decompression in select patients.
}

https://thejns.org/doi/abs/10.3171/2016.9.SPINE16469

KEY WORDS bony neoplasm; calcium deposition; craniovertebral junction; dysphagia; transoral decompression; tumoral calcinosis; cervical spine

$\mathrm{T}$ UMORAL calcinosis (TC) is a rare clinical syndrome caused by calcium deposition in periarticular soft tissue. Most commonly, TC affects the joints of the upper limbs and the hips; however, it is known to involve the articular surfaces of the cervical, thoracic, and lumbar spine..$^{10}$ In cases of spinal involvement, direct compression of neural elements and/or surrounding anatomical structures causes clinical symptoms that can be treated with direct surgical decompression. ${ }^{1,3,4,8,15,16,20,23,25-28,30,32,33}$ Awareness of TC is essential for spine surgeons because surgical specimens can be misdiagnosed if a neoplasm is suspected as the primary diagnosis. ${ }^{8}$

Few authors have reported on the diagnosis and management of TC in the cervical spine, $1,4,8,15,20,23,25,26,30$ likely due to the rarity of this condition and the diagnostic dilemma that it presents for clinicians. ${ }^{8,30}$ Furthermore, patients with $\mathrm{TC}$ at the craniovertebral junction (CVJ) may present with unique symptomatology and require a different treatment paradigm. Herein, we report a unique case of TC affecting the CVJ in a patient who presented with severe dysphagia. The lesion was successfully treated by transoral decompression without fusion. To our knowledge, this is the first case of TC affecting the CVJ that has been treated using the transoral approach. We review the clinical presentation, radiographic findings, and surgical management of $\mathrm{TC}$ in the $\mathrm{CVJ}$ of this patient.

\section{Case Report}

History and Examination

A 60-year-old woman with a history of hypertension presented to our clinic with progressive dysphagia and mild neck pain of 1 year's duration. The patient's symptoms had progressed to the point that she could tolerate only a liquid diet for the past 8 months. She denied any focal motor weakness, sensory symptoms, or gait disturbance. On physical examination, she exhibited full strength in all muscle groups, with no evidence of myelopathy; however, a large protrusion was visible on examination of the posterior pharynx. A preoperative swallow evaluation performed by speech therapy staff revealed oropharyngeal mass effect as the cause of the patient's dysphagia. A CT scan of the cervical spine revealed a calcified mass centered near the left $\mathrm{C} 1-2$ facet, causing compression of the pharynx ventrally (Fig. 1A-C). MRI demonstrated a $\mathrm{T} 1$ and $\mathrm{T} 2$ hypointense mass with minimal retropulsion 


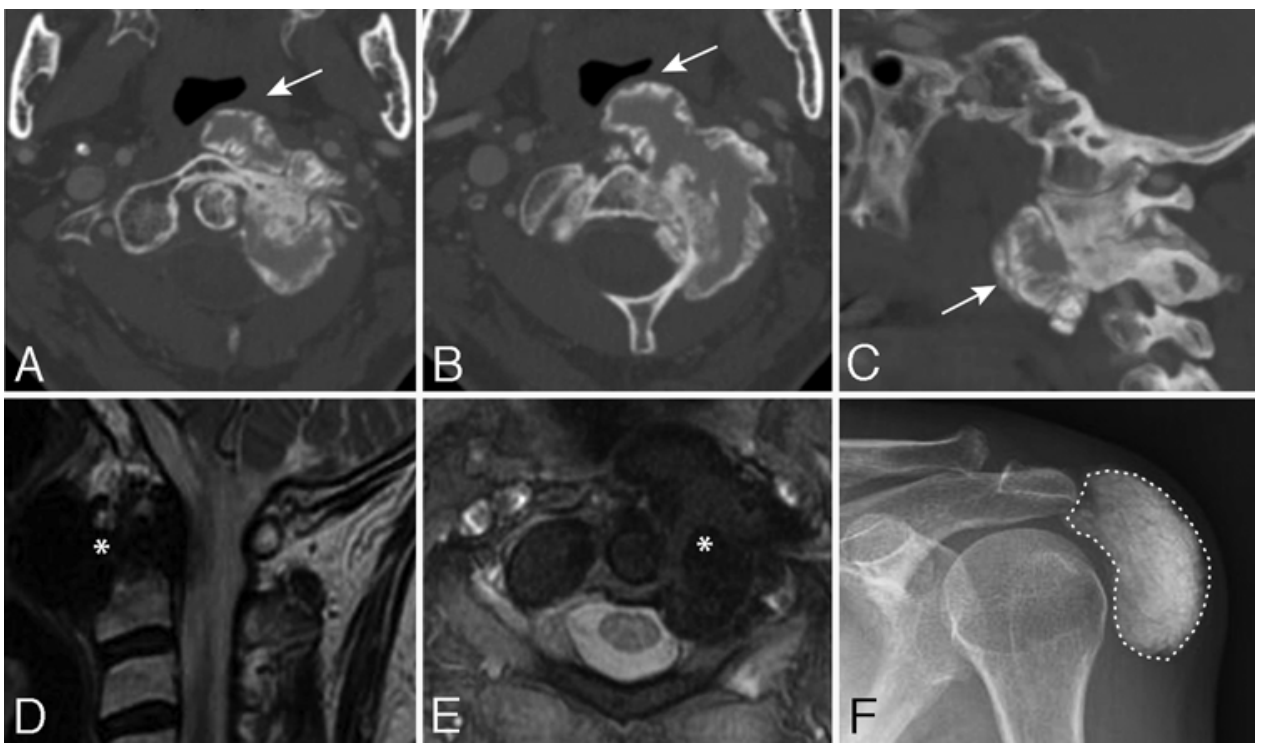

FIG. 1. A and B: Axial CT scans demonstrating a calcified mass at C-1 (A) and C-2 (B) with compression of the oropharynx (arrows). C: Sagittal CT scan demonstrating ventral extension of the mass (arrow). D and E: Sagittal (D) and axial (E) T2-weighted MR images demonstrating the hypointense mass (asterisk) with minimal canal compromise or cord compression. F: Left shoulder radiograph demonstrating a separate calcified lesion adjacent to the acromion (dashed outline).

(Fig. 1D and E). A radiograph of the left shoulder showed a large calcified mass adjacent to the acromion (Fig. 1F).

\section{Surgical Treatment}

In light of the patient's severe, progressive dysphagia, surgical decompression via a transoral approach was offered as a treatment option. The patient was brought to the operating room and intubated under general anesthesia. Her head was placed in a Mayfield head holder, and the $\mathrm{O}$-arm Surgical Imaging System (Medtronic plc) was used to register image guidance (Video 1).

VIDEO 1. Operative video demonstrating the transoral approach for decompression of tumoral calcinosis involving the craniovertebral junction. Narration by the senior author (N.T.). Copyright Barrow

Neurological Institute, Phoenix, Arizona. Published with permission. Click here to view.

The Spetzler-Sonntag transoral retractor (Integra LifeSciences Corp.) was then placed (Fig. 2A), and the operative field was prepared. A posterior pharyngeal mass was readily identifiable. A midline incision was made, and white "chalky" fluid was easily evacuated (Fig. 2B). The resection was continued deep and laterally, with the aid of image guidance to decompress the region while sparing the anterior arch of $\mathrm{C}-1$ and the left $\mathrm{C} 1-2$ facet (Fig. $2 \mathrm{C}-\mathrm{F}$ ). Pathological examination of an intraoperative frozen specimen indicated a benign process with masses of amorphous deposits of calcium hydroxyapatite surrounded by a histiocytic and giant cell reaction. After adequate decompression of the lesion, the oropharynx was closed in a single layer, and a feeding tube was passed beyond the oropharynx under direct visualization.

\section{Postoperative Course}

Upon awakening, the patient was neurologically stable. She remained intubated for 48 hours, as is routine for transoral approaches at our institution, and she was subsequently extubated without difficulty. She was administered broad-spectrum antibiotics for 4 days to protect against a potential infection due to oral flora. The feeding tube was left in place over the 4 days to facilitate surgical wound healing and provide nutrition. The patient's diet was subsequently advanced under the guidance of speech therapy staff, and she was tolerating a soft diet on discharge from the hospital. The final pathology results revealed dystrophic calcification, consistent with TC. Postoperative dynamic radiographs demonstrated stability of the CVJ. The patient had no complications on discharge from the hospital. At 12 months after the operation, dynamic radiographs demonstrated stability of the CVJ, and CT of the cervical spine showed no recurrence of the lesion. At the 14-month clinical follow-up, the dysphagia had significantly improved, and the patient was tolerating a solid diet.

\section{Discussion}

\section{Tumoral Calcinosis}

The term "tumoral calcinosis" was first used in 1943 by Inclan et al., ${ }^{14}$ but the condition was first described by Duret in $1899 .{ }^{9}$ It is a pathological condition defined by the presence of calcium hydroxyapatite crystals in periarticular soft tissue. Most patients have multiple lesions that remain asymptomatic until the persistent growth of the lesions leads to local mass effect, causing pain or compression of neurovascular structures. . $^{10,30}$ TC can be separated into 3 subtypes-familial, sporadic, and secondary to chronic renal disease ${ }^{26}$ - and $23 \%$ of cases are associated with a primary metabolic disorder such as hyperphosphatemia. ${ }^{5,31}$

CT and MRI are complementary radiological studies for lesions in patients with TC. A CT study typically demonstrates an irregular, lobulated, isodense-to-hyperdense 

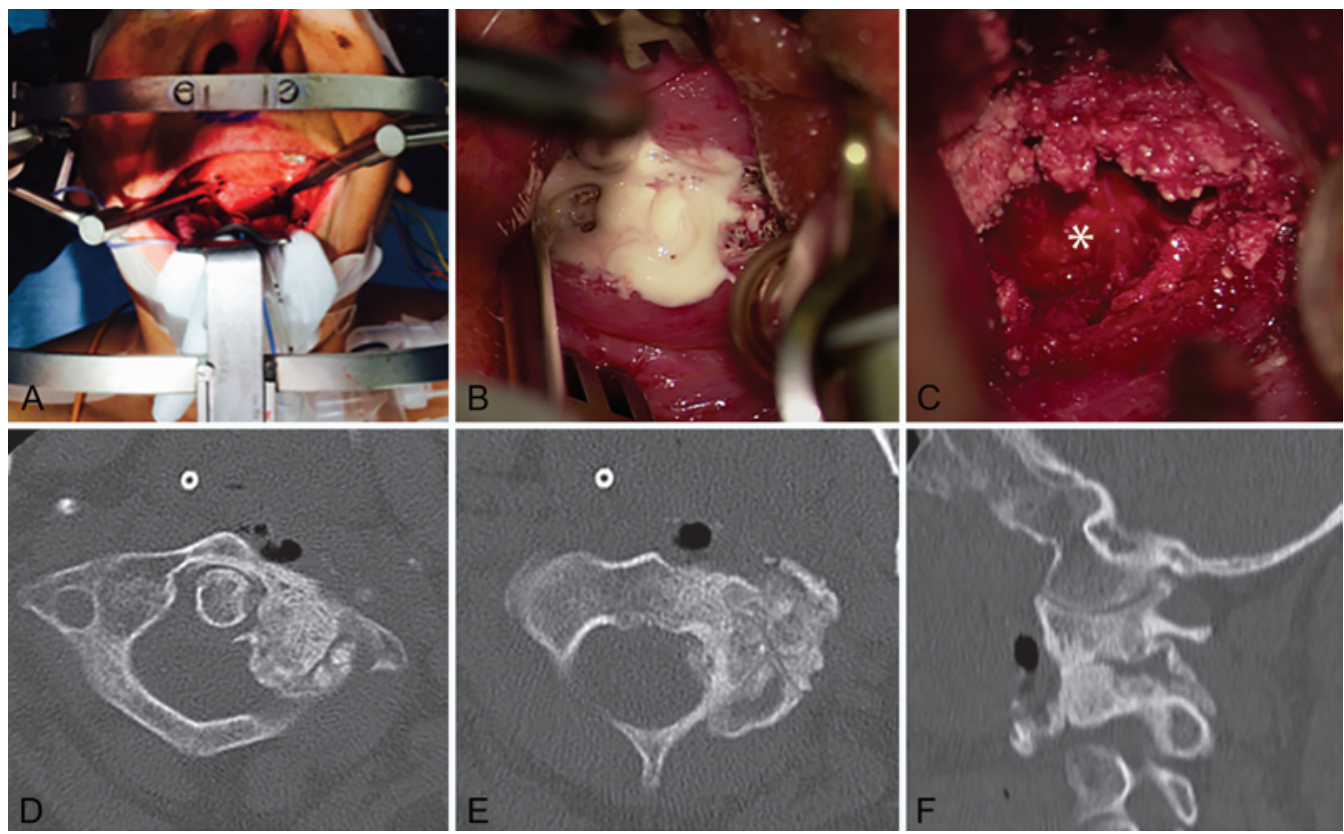

FIG. 2. A: Preoperative positioning with the Spetzler-Sonntag retractor in place. B: Initial evacuation of the lesion upon incision of the oropharynx. C: Resection cavity with the anterior aspect of $\mathrm{C} 1-2$ (asterisk) in the deep portion of the operative field. D-F: Corresponding postoperative axial ( $D$ and $E$ ) and sagittal $(F) C T$ scans demonstrating the extent of resection. Figure is available in color online only.

mass that may exhibit septations or fluid levels due to the layering of calcified fluid. ${ }^{2,13,17-19,29}$ MRI typically demonstrates intermediate- to low-signal intensity of T1/T2 sequences and little to no contrast enhancement, as was seen in our patient (Fig. 1).

Although TC of the spine can be confused with other more malignant pathologies ${ }^{8}$ the primary differential diagnosis of systemic TC includes the crystal deposition arthropathies gout and pseudogout. The clinical history and histological diagnosis typically distinguish these entities, with gout demonstrating negatively birefringent crystals under polarizing light, pseudogout demonstrating positively birefringent crystals, and TC demonstrating nonbirefringent crystals. Grossly, TC often has a chalky white texture associated with retained calcified fluid and a honeycomb appearance surrounding the lesion; both of these features were readily apparent in our patient (Fig. 2). TC is not usually associated with the adjacent bony destruction seen in patients with crystal pseudarthropathies. ${ }^{3,26}$ It has been noted that incomplete resection of TC in other locations can lead to recurrence and that continued clinical and radiographic follow-up for these patients is essential in the years following an operation. ${ }^{10,20}$

\section{TC of the Cervical Spine and the CVJ}

Although TC typically affects the hip joints and the joints of the upper extremities, spinal involvement has been described. ${ }^{26}$ Cases involving both the vertebral bodies and the posterior elements have been reported, with most cases involving the lumbar spine., 3,8,28,32,33 Twelve cases have been reported that involved the cervical spine, and most of these patients presented with neck pain and/ or symptoms of spinal cord compression (Table 1).,1,8,15,
20,23,25,26,30 Only 3 cases of TC involved C-1 and/or C-2; the remaining cases involved the middle to lower cervical spine. Most patients with cervical TC have been treated with posterior decompression with or without fusion; none have been treated with transoral decompression.

Of the 3 reported cases of TC affecting the C1-2 levels, only 1 patient had TC involving the anterior elements at these levels. Chang et al. ${ }^{4}$ reported the case of a 44 -yearold woman who presented with posterior neck pain and headaches and was found to have a periodontoid mass causing C-2 nerve root and spinal cord compression. Although the TC in this case involved the odontoid and ventral components of $\mathrm{C} 1-2$, the lateral nature of the mass and the associated neural compression prompted a posterior decompression and occipital to C-5 fixation.

The other 2 cases of TC affecting C1-2 were also treated with posterolateral decompression, 1 with and 1 without fusion. Mooney and Glazier ${ }^{23}$ reported the case of a 17-month-old boy who presented with torticollis and was found to have a calcified mass at the lateral aspect of C-1, where it was encroaching on the spinal canal. The lesion was resected via a far-lateral approach, followed by a partial C-1 laminectomy with no fusion performed. Durant et al. ${ }^{8}$ reported the case of a 78-year-old man who underwent posterior decompression and fusion for presumed rheumatoid pannus; however, the histopathology revealed TC. No other details regarding patient symptoms or imaging were provided in their report.

Of note, our literature review identified several cases of calcium deposition at the CVJ that were thought to represent TC but were not confirmed by histology.,16,21 The report by Kokubun et al. ${ }^{16}$ has been cited as one of the original descriptions of TC in the cervical spine; however, 
TABLE 1. Published reports of tumoral calcinosis of the cervical spine

\begin{tabular}{lcllll}
\hline \multicolumn{1}{c}{ Authors \& Year } & Pt Age (yrs) & Level & \multicolumn{1}{c}{ Position } & \multicolumn{1}{c}{ Clinical Presentation } & \multicolumn{1}{c}{ Treatment } \\
\hline Agarwal et al., 1993 & 45 & C5-6 & Posterior & Pain, weakness & Laminectomy \\
\hline Ohashi et al., 1996 & 12 & C3-6 & Posterolateral & Torticollis & Surgical excision \\
\hline Mooney \& Glazier, 1997 & 1.5 & C1-2 & Lateral & Torticollis & Posterolateral decompression \\
\hline Durant et al., 2001 & 78 & C1-2 & NS & NS & Posterior excision/fixation \\
\cline { 2 - 5 } & 61 & C7-T1 & NS & NS & Posterior laminectomy \& fusion \\
& 48 & C3-4 & Posterolateral & NS & Laminectomy \\
\hline Matsukado et al., 2001 & 54 & C4-5 & Posterior & NS & Posterior decompression/laminoplasty \\
\hline Qadri et al., 2005 & 51 & C7-T1 & Posterior & Myelopathy & Laminectomy \& excision \\
\hline Teng et al., 2006 & 59 & C3-6 & Posterior & Neck pain/weakness & Laminectomy \& fusion \\
\hline Jackson et al., 2007 & 29 & C6-T2 & Posterior & Pain, paresthesia & Anterior plus posterior decompression \& fusion \\
\hline Chang et al., 2013 & 44 & C1-2 & Anterior & Headache & C-1 laminectomy, occiput-C5 fixation \\
\hline Current report & 60 & C1-2 & Anterior & Dysphagia & Transoral decompression \\
\hline
\end{tabular}

NS = not specified; $\mathrm{Pt}=$ patient

the histological diagnosis was actually consistent instead with calcium pyrophosphate dehydrate deposition disease. This highlights the difficulty in diagnosing these lesions and emphasizes the need for awareness of this pathology. Our case is the fourth reported case of histologically confirmed TC affecting $\mathrm{C} 1-2$, and the first case involving treatment with transoral decompression.

\section{Dysphagia at the CVJ}

As it was with our patient, dysphagia is a common presenting symptom for patients with CVJ pathology. In a previous review of 148 patients with ventral foramen magnum lesions, Dickman et al. ${ }^{7}$ identified 29 patients $(20 \%)$ who presented with dysphagia prior to surgery. Further examination of these patients revealed that $18(12 \%)$ had uncoordinated swallowing and that $26(18 \%)$ had a decreased gag reflex. Of note, this analysis included all patients who underwent transoral decompression for any pathology, with most of the 148 patients having rheumatoid arthritis ( $n=58$ [39\%]), congenital malformations $(n=37$ [25\%]), or chronic dens dislocations $(n=29$ [20\%]). The series included no case of calcium hydroxyapatite, uric acid (gout), or calcium pyrophosphate (pseudogout). In a more recent report from Fenoy et al.,1 21 patients with calcium pyrophosphate deposition at the CVJ were specifically analyzed. Of these 21 patients, 3 (14\%) presented with dysphagia as a prominent symptom, and 6 (29\%) were found to have lower cranial nerve deficits. No patient identified in our literature review of TC presented with dysphagia or lower cranial nerve deficits (Table 1).

\section{The Transoral Approach}

The transoral approach provides direct access to ventral midline pathology at the CVJ, and it has been well described for extradural lesions in this region. ${ }^{7}$ The transoral approach is best suited for a compressive pathology of the brainstem and spinal cord from the clivus to the level of approximately C-3, and extended transoral exposures (e.g., transoral-translabiomandibular and transoraltransmaxillary) have been adapted for more extensive le- sions. Numerous variations of the transoral approach have been described in the medical literature, and most cases are performed for basilar invagination from various pathologies. ${ }^{6,12,22}$ Nonetheless, no previous reports exist of the transoral approach being performed for TC, so the current case report adds to the existing indications for this procedure.

The main limitation of the transoral technique is approach-associated morbidity. Complications include, but are not limited to, cerebrospinal fluid leak or fistula formation, meningitis, oral wound dehiscence or wound infection, need for prolonged parenteral nutrition, respiratory failure, cerebrovascular injury, and delayed occipitocervical instability. 6,7,11,12,22,24 Rates of complications vary greatly among series; however, the incorporation of perioperative broad-spectrum antibiotics, utilization of image guidance, and consideration of simultaneous or staged posterior fixation are relatively recent interventions that have improved the perioperative morbidity associated with the transoral approach. In our current practice, we use broad-spectrum antibiotics (clindamycin and ceftriaxone sodium) for 4 days postoperatively to reduce the oral flora and a feeding tube for the same period to facilitate wound healing. In addition, we use intraoperative imaging and navigation, which we believe facilitates the identification of anatomical landmarks and optimizes the extent of resection of pathology. In the present case, the comparison of dynamic radiographs obtained preoperatively and postoperatively confirmed stability across the CVJ, and thus obviated the need for posterior fixation.

\section{Conclusions}

TC is a calcium deposition disorder that can result in tumor-like lesions in the spine, causing local mass effects. Involvement of the $\mathrm{CVJ}$ is rare but may be amenable to transoral decompression. In this case of $\mathrm{TC}$ at the $\mathrm{CVJ}$, decompression alone was adequate to relieve the patient's dysphagia, and fusion was not required. Neurosurgeons should be aware of this pathology and include it in the dif- 
ferential diagnosis of lesions in this region because prompt recognition facilitates its diagnosis and treatment.

\section{References}

1. Agarwal R, Burns RR, Vergne-Marini P: Paraparesis due to massive ectopic paravertebral calcification in a patient on maintenance hemodialysis. Am J Kidney Dis 22:717-720, 1993

2. Barnacle AM, Gower PE, Mitchell AW: Ultrasonography of acute and chronic tumoral calcinosis. Clin Radiol 57:146149,2002

3. Carlson AP, Yonas HM, Turner PT: Disorders of tumoral calcification of the spine: illustrative case study and review of the literature. J Spinal Disord Tech 20:97-103, 2007

4. Chang CC, Sung CC, Hsia CC, Lin SH: Uremic tumoral calcinosis causing atlantoaxial subluxation and spinal cord compression in a patient on continuous ambulatory peritoneal dialysis. Int Urol Nephrol 45:1511-1516, 2013

5. Cofán F, García S, Campistol JM, Combalia A, Oppenheimer F, Ramón R: Ulnar nerve compression - a case of giant uremic tumoral calcinosis. Acta Orthop Scand 68:302-304, 1997

6. Crockard HA, Pozo JL, Ransford AO, Stevens JM, Kendall BE, Essigman WK: Transoral decompression and posterior fusion for rheumatoid atlanto-axial subluxation. J Bone Joint Surg Br 68:350-356, 1986

7. Dickman CA, Spetzler RF, Sonntag VKH, Bambakidis NC, Apostolides PJ: Transoral approach to the craniovertebral junction, in Bambakidis NC, Dickman CA, Spetzler RF, et al (eds): Surgery of the Craniovertebral Junction, ed 2. New York: Thieme, 2012, pp 277-289

8. Durant DM, Riley LH III, Burger PC, McCarthy EF: Tumoral calcinosis of the spine: a study of 21 cases. Spine (Phila Pa 1976) 26:1673-1679, 2001

9. Duret MH: Tumours multiples et singulieres des bourses sereuses. Bull Mem Soc Anat Paris 74:725-733, 1899

10. Fathi I, Sakr M: Review of tumoral calcinosis: A rare clinico-pathological entity. World J Clin Cases 2:409-414, 2014

11. Fenoy AJ, Menezes AH, Donovan KA, Kralik SF: Calcium pyrophosphate dihydrate crystal deposition in the craniovertebral junction. J Neurosurg Spine 8:22-29, 2008

12. Hadley MN, Spetzler RF, Sonntag VK: The transoral approach to the superior cervical spine. A review of 53 cases of extradural cervicomedullary compression. J Neurosurg 71:16-23, 1989

13. Hug I, Gunçaga J: Tumoral calcinosis with sedimentation sign. Br J Radiol 47:734-736, 1974

14. Inclan A, Leon PP, Camejo M: Tumoral calcinosis. JAMA 121:490-495, 1943

15. Jackson W, Sethi A, Carp J, Talpos G, Vaidya R: Unusual spinal manifestation in secondary hyperparathyroidism: a case report. Spine (Phila Pa 1976) 32:E557-E560, 2007

16. Kokubun S, Ozawa H, Sakurai M, Tanaka Y: Tumoral calcinosis in the upper cervical spine: a case report. Spine (Phila Pa 1976) 21:249-252, 1996

17. Kolawole TM, Bohrer SP: Tumoral calcinosis with "fluid levels" in the tumoral masses. Am J Roentgenol Radium Ther Nucl Med 120:461-465, 1974

18. Longacre AM, Sheer AL: Tumoral calcinosis, case presentation and review of 55 cases in the literature. JFMA 61:221225,1974

19. Martinez S, Vogler JB III, Harrelson JM, Lyles KW: Imaging of tumoral calcinosis: new observations. Radiology 174:215-222, 1990

20. Matsukado K, Amano T, Itou O, Yuhi F, Nagata S: Tumoral calcinosis in the upper cervical spine causing progressive radiculomyelopathy-case report. Neurol Med Chir (Tokyo) 41:411-414, 2001
21. Mayr MT, Hunter S, Erwood SC, Haid RW Jr: Calcifying pseudoneoplasms of the spine with myelopathy. Report of two cases. J Neurosurg 93 (2 Suppl):291-293, 2000

22. Menezes AH, VanGilder JC: Transoral-transpharyngeal approach to the anterior craniocervical junction. Ten-year experience with 72 patients. J Neurosurg 69:895-903, 1988

23. Mooney JF III, Glazier SS: Tumoral calcinosis of the cervical spine in an infant. Case illustration. J Neurosurg 86:162, 1997

24. Mouchaty H, Perrini P, Conti R, Di Lorenzo N: Craniovertebral junction lesions: our experience with the transoral surgical approach. Eur Spine J 18 (Suppl 1):13-19, 2009

25. Ohashi K, Yamada T, Ishikawa T, Yamaguchi S, Nakajima $\mathrm{H}$, Takagi M: Idiopathic tumoral calcinosis involving the cervical spine. Skeletal Radiol 25:388-390, 1996

26. Qadri SR, Choksey MS, Shad A: Tumoural calcinosis of the cervical spine: case report, pathogenesis and differential diagnosis. Br J Neurosurg 19:185-190, 2005

27. Remy-Leroux V, Reguiaï Z, Labrousse AL, Zakine EM, Clavel P, Bernard P: [Tumoral calcinosis at an unusual site in a haemodialysis patient.] Ann Dermatol Venereol 136:350354, 2009 (Fr)

28. Riemenschneider PA, Ecker A: Sciatica caused by tumoral calcinosis; a case report. J Neurosurg 9:304-307, 1952

29. Steinbach LS, Johnston JO, Tepper EF, Honda GD, Martel W: Tumoral calcinosis: radiologic-pathologic correlation. Skeletal Radiol 24:573-578, 1995

30. Teng AL, Robbin MR, Furey CG, Easley SE, Abdul-Karim FW, Bohlman HH: Tumoral calcinosis in the cervical spine in a patient with CREST syndrome. A case report. J Bone Joint Surg Am 88:193-197, 2006

31. Tezelman S, Siperstein AE, Duh QY, Clark OH: Tumoral calcinosis. Controversies in the etiology and alternatives in the treatment. Arch Surg 128:737-745, 1993

32. Ward M, Curé J, Schabel S, Smith EA, Schumacher HR Jr, Silver RM: Symptomatic spinal calcinosis in systemic sclerosis (scleroderma). Arthritis Rheum 40:1892-1895, 1997

33. Watanabe A, Isoe S, Kaneko M, Nukui H: Tumoral calcinosis of the lumbar meninges: case report. Neurosurgery 47:230-232, 2000

\section{Disclosures}

The authors report no conflict of interest concerning the materials or methods used in this study or the findings specified in this paper.

\section{Author Contributions}

Conception and design: Theodore, Mooney, Oppenlander. Acquisition of data: Theodore, Mooney, Oppenlander. Analysis and interpretation of data: Theodore, Mooney, Oppenlander. Drafting the article: Theodore, Mooney, Oppenlander. Critically revising the article: Theodore, Mooney, Oppenlander. Reviewed submitted version of manuscript: Theodore. Administrative/technical/material support: all authors. Study supervision: Theodore.

\section{Supplemental Information \\ Videos}

Video 1. https://vimeo.com/190255264.

\section{Correspondence}

Nicholas Theodore, c/o Neuroscience Publications, Barrow Neurological Institute, St. Joseph's Hospital and Medical Center, 350 W Thomas Rd., Phoenix, AZ 85013.email: neuropub@ dignityhealth.org. 